\title{
The promise of COVID-19 vaccines. Authors' reply
}

\author{
Justyna M Sokolska', Jacek Kurcz², Wojciech Kosmala' \\ 'Department of Cardiovascular Imaging, Institute of Heart Diseases, Wroclaw Medical University, Wrocław, Poland \\ 2Department of Radiology, Wroclaw Medical University, Wrocław, Poland
}

\author{
Correspondence to: \\ Justyna Sokolska, MD, PhD, \\ Department of Cardiovascular \\ Imaging, \\ Institute of Heart Diseases, \\ Wroclaw Medical University, \\ Borowska 213, 50-556 Wrocław, \\ Poland \\ phone: +48717364200 , \\ email: \\ justyna.sokolska@umw.edu.pl \\ Copyright by the Author(s), 2022 \\ DOI: 10.33963/KP.a2022.0002 \\ Received: \\ December 22, 2021 \\ Accepted: \\ December 22, 2021 \\ Early publication date: \\ January 4, 2022
}

We appreciate the interest in our report on acute myocarditis following the first dose of COVID-19 mRNA vaccination in a 21-year-old man shown by Kounis et al. [1]. We would like to thank them for their valuable remarks and take the opportunity to respond to their comments [2]. Due to word count limitations in the clinical vignette section, we were not able to cover all the important aspects of this topic; therefore, we are grateful to Kounis et al. for their discussion on some meaningful issues regarding this complication. The pathophysiology of myocarditis following SARS-CoV-2 infection and/or COVID-19 vaccination remains unclear. We agree with the concept proposed by Kounis et al. [1] that a hypersensitivity reaction induced by a vaccine component might be one of the possible mechanisms leading to acute myocarditis following COVID-19 vaccination [2]. Another likely explanation might be that vaccine-mediated expression of SARS-CoV-2 surface spike protein on cardiomyocytes could be a potential trigger for an immune response and a cause of organ-specific cell death $[3,4]$. Both hypotheses need further investigation.

We do not have pathomorphological data on the type of myocarditis in our patient, as we do not routinely perform a myocardial biopsy in non-complicated and unequivocal cases of acute myocarditis diagnosed with advanced cardiac imaging. The pharmacological treatment of the most common viral or, as in our case, vaccine-induced acute myocarditis is still under debate; however, most experts support the recommendation to avoid sports and high-intensity exercises during the first three to six months of convalescence [5]. Unfortunately, there are no up-to-date guidelines issued by the European Society of Cardiology that specifically focus on myocarditis.
Recently, Patone et al. [3] published a very interesting paper on risks of myocarditis, pericarditis, and cardiac arrhythmias associated with COVID-19 vaccination or SARS-CoV-2 infection. In their large observational study (more than 38.6 million adults) carried out in England, $0.001 \%$ of patients had myocarditis within 1-28 days post any dose of COVID-19 vaccine. The authors estimated that within 28 days following the first dose of vaccination myocarditis can occur in an extra two (vaccine ChAdOx1, Astra Zeneca), one (BNT162b2 mRNA, Pfizer) and six (mRNA1273, Moderna) patients per 1 million people vaccinated. It could also occur in ten patients per 1 million vaccinated in the first 28 days after the second dose of mRNA-1273 (Moderna). Interestingly, subgroup analyses showed that an increased risk of myocarditis following two mRNA vaccines (Pfizer, Moderna) was present only in patients younger than 40. For comparison, an extra forty myocarditis events per 1 million patients were observed in the population with a positive SARS-CoV-2 test [3].

We would like to take this opportunity to inform the readers of Kardiologia Polska (Kardiol Pol, Polish Heart Journal) about the follow-up examination, which was performed on our patient six months after the episode of acute myocarditis. His clinical condition improved after he had avoided physical activities in the last few months. Cardiac magnetic resonance imaging revealed significant improvements: normal-sized cardiac chambers with normal systolic function, no signs of persistent myocardial edema but with the remaining presence of subtle subepicardial late gadolinium enhancement, which was nonetheless much less prominent than in the first study (Figure 1) [1]. 


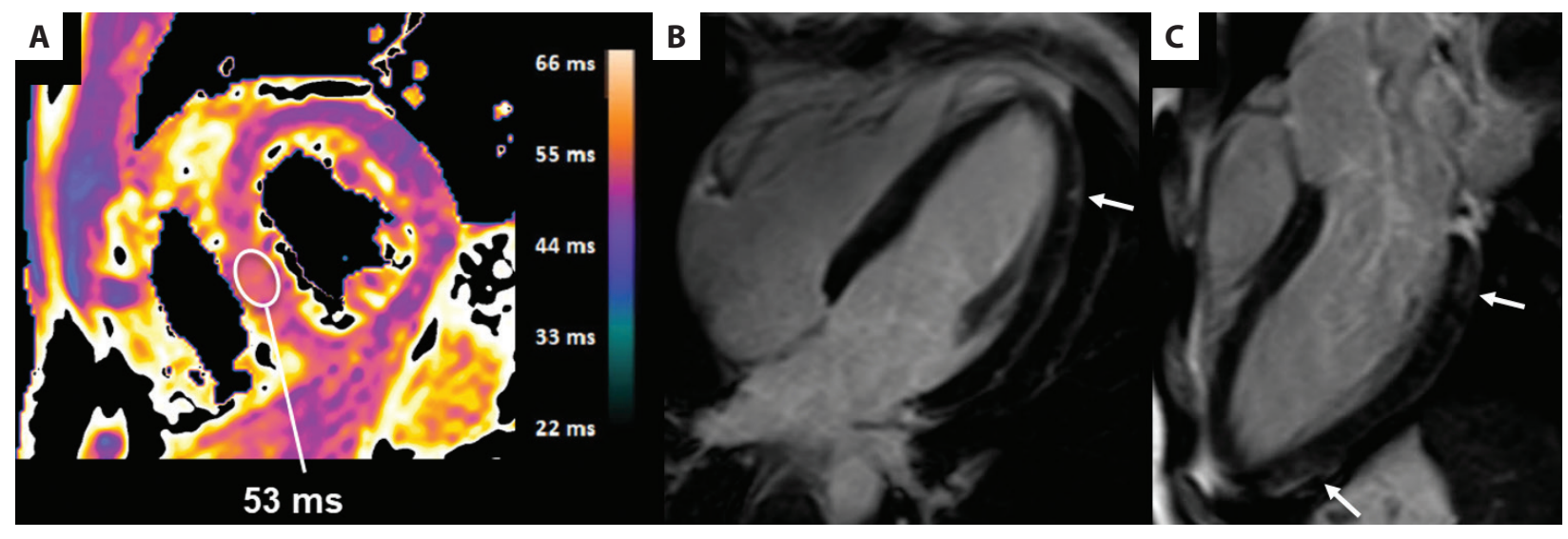

Figure 1. Cardiac magnetic resonance imaging demonstrating significant improvement six months after acute myocarditis following the first dose of COVID-19 vaccination in a 21-year-old man. A. T2 mapping showing a reduction of global myocardial edema (a decrease from 62 to $53 \mathrm{~ms}$ ), short-axis view. B, C. A decrement of diffuse subepicardial late gadolinium enhancement (arrows) in comparison to the baseline study, 4- and 3-chamber view) [1]

In conclusion, we firmly believe that the potential risks of adverse events following COVID-19 vaccinations are marginal in comparison with the risks of severe complications of SARS-CoV-2 infection. Further studies are needed to ensure the highest safety and quality of provided vaccines and to better understand the pathophysiology behind rare cases of acute myocarditis following vaccinations against COVID-19.

\section{Article information}

Conflict of interest: None declared.

Open access: This article is available in open access under Creative Common Attribution-Non-Commercial-No Derivatives 4.0 International (CC BY-NC-ND 4.0) license, allowing to download articles and share them with others as long as they credit the authors and the publisher, but without permission to change them in any way or use them commercially. For commercial use, please contact the journal office at kardiologiapolska@ptkardio.pl.

\section{REFERENCES}

1. Sokolska J, Kurcz J, Kosmala W. Every rose has its thorns - acute myocarditis following COVID-19 vaccination. Kardiol Pol. 2021;79(10): 1153-1154, doi: 10.33963/kp.a2021.0075, indexed in Pubmed: 34331307.

2. Kounis NG, Mplani V, Koniari I, et al. Hypersensitivity myocarditis and COVID-19 vaccines. Kardiol Pol. 2022; 80(1), doi: 10.33963/KP.a2021.0166, indexed in Pubmed: 34856634.

3. Patone $M, M e i X$, Handunnetthi L, et al. Risks of myocarditis, pericarditis, and cardiac arrhythmias associated with COVID-19 vaccination or SARSCoV-2 infection. Nat Med. 2021; 2021, doi: 10.1038/s41591-021-01630-0.

4. Bozkurt B, Kamat I, Hotez P. Myocarditis with COVID-19 mRNA vaccines. Circulation. 2021; 144(6): 471-484, doi: 10.1161/circulationaha.121.056135, indexed in Pubmed: 34281357.

5. Pelliccia A, Sharma S, Gati S, et al. 2020 ESC Guidelines on sports cardiology and exercise in patients with cardiovascular disease. Eur Heart J. 2020; 42(1): 17-96, doi: 10.1093/eurheartj/ehaa605, indexed in Pubmed: 32860412 . 